\title{
Introduction to the Special Series of Papers on Informing Each Other: Bridging the Gap between Researcher and Practitioners
}

\section{Brian Fitzgerald \\ College of Informatics \& Electronics, University of Limerick, Ireland}

\author{
bf@ul.ie
}

\begin{abstract}
As an applied discipline, the gap between IS theory and practice is a potentially worrying one. This special series focuses on this gap, and the papers published consider the problems in some detail and how they might be addressed from a high level view and also in the context of specific initiatives which have been undertaken successfully. The issue is framed by this paper which considers the bipolar gap between theory and practice, a futile scenario in which both poles are ultimately cold.
\end{abstract}

Keywords : Information Systems, Information Science, Theory and Practice, Relevance and Rigour

\section{Background: Relevance of Research to Practice?}

The gap between theory and practice is succinctly captured in the following:

In theory, there is no difference between theory and practice.

In practice, there is!

The theme of this special series is to explore the gap between research and practice and to consider how theory and practice can best inform each other. Each of the papers presented considers this in some way. This is particularly important in an applied discipline such as IS, and, while it is usually acknowledged (especially by academic researchers) that theory should inform practice, it is also undoubtedly the case that practice should inform theory. This view is supported by the fact that practice has often preceded theory in the IS field. The systems development life-cycle and prototyping were both areas in which practice led theory, as were programming style, compiler writing, user-interface design. Also, the Sage missile-defense system and the SABRE airline reservation system, developed in the 1950s and 1960s, were both examples of sophisticated interactive systems that far exceeded the maturity of the theory at the time.

The charge frequently levelled against IS research is that it is of little relevance to practitioners, a charge that is not confined solely to IS research, but to organisational and management science research in ge neral (Benbasat and Zmud, 1999). Benbasat and Zmud cite some negative opinions from business school

Material published as part of this journal, either on-line or in print, is copyrighted by the publisher of Informing Science. Permission to make digital or paper copy of part or all of these works for personal or classroom use is granted without fee provided that the copies are not made or distributed for profit or commercial advantage AND that copies 1) bear this notice in full and 2) give the full citation on the first page. It is permissible to abstract these works so long as credit is given. To copy in all other cases or to republish or to post on a server or to redistribute to lists requires specific permission and payment of a fee. Contact Editor@inform.nu to request redistribution permission. deans about academic research, who state that "as much as $80 \%$ of management research in the field may be irrelevant," and further that academics "say nothing in these articles and they say it in a pretentious way" (to which an academic would probably respond, "Pretentious? Moi?").

However, it is not just the opinion of academic deans. There is much evidence of the perception of irrelevance by practitioners. In 1995, the Society of Information Management (SIM) decided to 
Informing Each Other

end their practice of bundling a subscription to MIS Quarterly, regarded by many as the premier IS journal (and regarded by many as not!) as part of their membership fee. When subscription became voluntary, few SIM members chose to subscribe to MIS Quarterly, even at a heavily discounted price. This, despite the fact that the journal's mission is to publish research targeted at information system managers.

Confirmation of the negative perception of practitioners of scholarly IS publications is common. Khazanchi (2001) reports the following:

Academic research, if it canned (sic) be called that, is usually aimed at providing subsidized vacation opportunities for faculty and staff. Paper acceptance is generally determined by the number of paid attendees required to cover the hotel and personal costs of the organizers.

This is pretty blunt. Even the presumably misspelled "canned" could be interpreted as a Freudian slip in so far as it is suggestive of what one might do with academic research. Confirming this perception, Denning (1993) states that critics of university research have labelled it as "the scientists' welfare system that has many of the same scandals and defects of the social welfare system." While these criticisms may seem strong, the concept of an 'airplane ticket paper' is not unknown, that is, writing a paper primarily to get funding to travel to a desired exotic location.

A very graphic illustration of the negative perception of academic research occurred at a premier international IS conference a few years ago: A very successful IS practitioner delivered an extremely insightful and thoroughly entertaining plenary address to the assembled congregation of IS academics. This was not one of those occasions where the academic audience publicly applauded politely and then later privately scornfully dismissed it as excessively simplistic and deterministic (an all too frequent scenario, unfortunately). At the end of the plenary session, the Conference Chair thanked the practitioner, and as a gesture of appreciation offered him the weighty, multi- volume set of the Conference Proceedings. Even before the dismay registered on the face of the speaker (and it did), the audience erupted into spontaneous laughter. Yet, if the very idea that a successful practitioner could learn from the most leading-edge research in the IS field is a source of hilarity even to academics, then, as an applied discipline, IS clearly has a credibility problem. As a postscript, to the story, it is worth noting that the practitioner left the Conference without his 'gift'.

But is relevance to practice an important issue for IS researchers? One might presume so since some steps have been taken to try ensure that IS research is more relevant to practice. The aforementioned MIS Quarterly created an Executive Summary feature to make its research more accessible. Presumably, since SIM cancelled the automatic subscription of its members, it was not actually perceived by the practitioners as relevant. Another attempt to bridge the gap to practice is to have practitioners deliver keynote addresses at academic conferences, but as mentioned above, these are often judged as overly simplistic and unstimulating by academic participants.

Some evidence that academics don't really care about relevance to a practitioner audience is the fact that those journals that actually publish practitioner-oriented research are rated lower in academic tenure and promotional criteria. Yet, as Williams (2001) points out, "as rigorous as an academic journal may be, nothing is a greater professional risk than putting your ideas in front of 100,000 IT professionals for them to evaluate in a popular trade magazine." Thus, publishing in a 'rigorous' journal readership with a readership cast of hundreds is probably a significant safety factor for researchers.

Also, the publication cycle from paper submission to eventual journal publication can be measured in terms of years often. Thus, research on current challenges that practitioners face is not going to be available in an appropriate time-frame to be of any real use. There is no real evidence that any changes in the journal ranking criteria are being put in place to encourage submission to electronic journals, which could deliver the information quicker to the audience. In a similar fashion, the publication cycle time for 
conferences is much quicker than journals, and if timeliness of communicating research results to practitioners was important, then conference publications should be rated higher than journal publications, but this is clearly not the case.

Furthermore, the acceptance criteria for research publication are actually biased against practitioner papers. Thus, even when conference organisers and journal editors solicit papers from practitioners, the review process is often still mired in the standard regulations, thus resulting in rejection of these papers.

\section{Relevance to Whom?}

The above would clearly suggest that research is not perceived as directly relevant by practitioners. Adding to the problem is the fact that few researchers are former practitioners, or make any attempt to closely connect themselves with practice. Indeed, there is typically no reward system to encourage researchers to become intimately associated with IS practice. Those IS academics who do turn their hand to commercial endeavours are often seen as avaricious treasure hunters. Also, former practitioners who return to academe are not well respected, and their professional expertise is completely undervalued (Heart, 2001).

\section{Relevance to Students?}

So if IS research is not directly relevant to practitioners, who else might it be relevant to? An argument frequently proposed is that IS research is relevant to students, be they undergraduates, graduate research students, or on executive MBA programmes. In this case, the argument generally takes the form of the strength of "weak ties" connection. That is, it is assumed that research papers would not be directly accessible to a practitioner audience, partly on the unspoken assumption that they do not have the intellectual training required to understand the 'depth' of the research. Academic researchers interpret their work and that of others in scholarly research papers and translate it into a more palatable form for the consumers. However, if the primary audience is the student one, then books would be much more highly regarded as a publication outlet. Yet, in the US, one study has ranked books as only worth 2.3 research papers, and in the research assessment exercise in the UK, books are not admissible at all. Yet, these are a publication format in which results can be provided in more readily digestible form for students.

Furthermore, if the primary consumer of academic research is indeed the student, then it might be expected that researchers would seek an increase in their number of teaching hours. Not likely! In fact, many researchers use their research grant funding to buy out their teaching hours.

Another argument which is used to explain and defend the perception of irrelevance in academic research is that research is part of a bigger picture, and viewing any individual paper in isolation does not reveal the overall coherent picture of the relevance of the research, whereas when viewed in its entirety over a stream of publications, the research might well be deemed relevant. However, if this were the case, again, books, which can depict a complete stream of research, would surely be more highly valued. Also, there would be more evidence of a cumulative tradition in relation to research being carried out by individuals and in research clusters. But this evidence is sadly lacking in IS research.

A similar argument which could be advanced is that academic research falls into two broad categories: applied research, which might be relevant in the sense that it is more immediately applicable, and basic research which is more esoteric, and perhaps of long-term benefit. Also, a basic research category would insulate researchers from the danger of being pushed into a research agenda dictated by the latest management or technological fad. This categorisation into basic and applied research is potentially useful, as research is never wholly predictable; therefore, research that seems esoteric and irrelevant today might be of enormous significance in the future. Examples might be research on neural networks that might be of enormous importance to organisations who possess a huge amount of information in various databases and who wish to uncover possible patterns in the data-insurance companies, for example. Like- 
Informing Each Other

wise, research today in biotechnology could play a similar role. However, if this was truly important to IS academics, the distinction between basic and applied research would be more formally established. Also, if there did exist a category of basic research, one could again expect more evidence of a cumulative tradition in certain basic research areas.

There is further compelling evidence that reaching a student, or indeed a practitioner, audience is quite a remote concern for IS researchers. As already mentioned, conference proceedings, with their short publication life-cycle and constant updating of research themes, represent a very good opportunity for disseminating relevant research in a timely fashion to both students and practitioners. However, these proceedings are printed in very limited print-runs by leading publishers who apply very strict copyright policies. The proceedings are ridiculously expensive (\$150 per copy is not unusual), which clearly makes them unattractive to both students and practitioners. It would seem to be a simple matter to use print production companies, or the Internet, to disseminate low-cost copies. However, the principal argument for using established publishers with their exorbitant prices is that these publishers are able to fulfil recurring orders from university libraries around the world, thus ensuring that these proceedings are available for other academic researchers.

\section{Relevance to Other Academics?}

Since IS researchers do not seem to strive to make their research relevant to practitioners or students, another obvious audience is other academics. Here, there is plenty of evidence of a quest for relevance. The whole canon of received wisdom on how to construct papers suggests that suitable homage be paid to previous research, even if it is only briefly to acknowledge the muddled fumblings of others. Also, the first and principal reviewers of these papers are other academics, so pleasing this audience is important, often to the extent of employing the well-established tactics of citing the work of those who are potential reviewers or editors, and citing work from the journal to which the research paper is being submitted.

Citation analysis has been elevated to a scientific form. Sophisticated analyses to see how many others have cited a piece of work are conducted and used as part of tenure and promotion applications. As a result, eliciting citations from other academics is a very important task. Also, since the citation is the important part, there is much superficial and transitive referencing whereby researchers provide blanket references to a whole stream of research. Also, it is a circular phenomenon since certain 'seminal' papers will be routinely cited, often perhaps without being actually read. Thus, there is much shallow knowledge of what the main papers relating to a particular topic are, but the deep knowledge of the content of these papers is by no means guaranteed. Impact on practice is not really considered. Rather, academics submit papers to conferences and journals at great personal cost, provide reviewing services for free, and then pay exorbitant sums of money for the privilege of reading these journals and conference proceedings. All this from the intelligentsia who can teach business strategy!

The model which can explain the apparently illogical behaviour of academics best arises in the economics of reputation signalling incentives (Lerner and Tirole, 2000). Summarising very briefly, signalling incentives is an umbrella term capturing both career concern and ego gratification incentives. The career concern incentive relates to the fact that academic researchers enhance future job prospects for tenure and promotion by publishing their work in scholarly journals. These publications are the principal criterion for career advancement. The ego gratification incentive is premised on peer recognition, which is very highly valued. Thus, research is pursued as an end itself, becoming a kind of hobby which is intrinsically satisfying. Also, the sense of belonging to a community is gratifying and fulfils basic human needs. The academic community with its often undocumented norms and taboos becomes a closed system in which relatively pointless research can be pursued and published ad infinitum. In such a system, the age-old problem of means-ends inversion occurs, in that rather than conducting and publishing research (the means) with a view to addressing some relevant research problem (the end), publishing the research becomes an end in itself, and its practical usefulness is forgotten about. 
Also, as a direct consequence of the career concern incentive, it is a more adaptive strategy to publish as frequently as possible. Slightly different papers, often with merely a change of title, are disseminated in as many outlets as possible. At first glance, this might appear to be a strategy for causing information overload, but most experienced academics understand the publication frequency, and can detect overlaps. Indeed, it is not uncommon for researchers to advise readers as to which of their papers is best in a range of publications that have slightly different titles. However, it is unlikely that students and practitioners understand the nuances of this publishing game.

In order to attract research funding to perpetuate this cycle of research, research proposals seeking funding are submitted to large and remote bureaucratic bodies. The decision makers who review these proposals are frequently other academics; thus, the academic paper is a language they understand. Even when practitioners are part of the reviewing body for these funding submissions, the academic language is not a neutral factor; rather, the persuasive and authoritative rhetoric is hard to discount, and the practitioner reviewer perhaps believes that there is real substance to the proposal, even if he or she cannot readily detect it.

\section{Papers in this Series}

The paper by Lang, "Communicating Academic Research Findings to IS Professionals: An Analysis of Problems," begins from the premise that research findings often do not have direct or immediate relevance to IS professionals in industry, and should not be expected to find a contemporary receptive audience. He offers some examples of this. However, he goes on to argue that the traditional mechanisms whereby academic researchers actually disseminate their work are prone to numerous communication breakdowns. He identifies three major problems, namely, the choice of dissemination channels, language barriers, and the alienation of academia from industry. He also suggests some practical recommendations for how each of these may be ameliorated to some extent.

The paper by Moody, "Using the World Wide Web to Connect Research and Professional Practice: Towards Evidence-Based Practice," also identifies the long time delay in the dissemination of research findings into practice, a process in which some findings are inevitably 'lost'. Moody identifies causes in both the 'demand side' and 'supply' side. He draws on concepts from the domain of knowledge management to further elucidate the problem. Similarly to Lang, Moody also focuses on the channel of communication between researchers and practitioners, but specifically discusses how information technology can address some of the problems identified. Two case studies are presented to illustrate the arguments. The first discusses the application of evidence-based medicine (EBM) to successfully support medical practitioners in making relevant medical advice available to them in the appropriate time-frame. This gap between research and practice in IS is considered to be analogous and the application of an EBM approach to address this is considered in the context of a joint project involving Monash University and the Australian Computer Society.

In their paper, "Regional IS Knowledge Networks: Elaborating the Theme of Relevance of IS Research," Söderström and Nordström, elaborate on the notion of relevance to whom, and identify a larger dimension, that of a geographic region, which should be considered. Drawing on the American pragmatism literature, they put forward the notion of a "regional IS knowledge network" and argue that this can achieve the two important goals of making IS researchers more aware of IS practice, and also of making IS practitioners more aware of IS research. While the first two papers in this issue deal with fairly high-level conceptualizations of the problem of the research-practice gap, this paper is more specific in its focus on actions that have already been taken, one of which was the design of a Masters program specifically suited to the needs of the region. They identify five important aspects which characterize the regional knowledge network: (1) the creation of knowledge is in focus, (2) there must be a working transfer of knowledge in both directions between researchers and practitioners within the network, 
(3) knowledge is distilled in collaboration between researchers and practitioners, (4) knowledge must be made public, and (5) knowledge should be turned into action.

In the final paper, "Integrating Theory \& Practice in Education with Business Games," Neville and Adam also offer very specific advice. In a similar vein to the previous paper by Söderström and Nordström, they discuss an innovative Masters programme. The primary objective of the programme, now in its fifth year, is to bridge the divide between theoretical and practical elements of the IT curriculum. One component which seeks to achieve this is a year-long project in the form of a business game whereby students form software companies and develop a system to solve the IT requirements of a fictitious company. The authors discuss the lessons learned from this exercise in some detail and offer a comprehensive conceptual framework which helps to address the gap between practical and theoretical issues in education.

\section{Conclusion}

As McLean (1973) aptly put it: "the proper place to study elephants is the jungle, not the zoo." More research is therefore needed in real contexts. In the early stages of a discipline, theory can best progress by examining good practice. All too often, however, theorists fail to consider practice when it might be appropriate to do so, and, vice versa, practitioners fail to heed theorists when it might be beneficial. Researchers have criticised the gap between theory and practice, whereby theorist and practitioners are isolated from each other and move in different directions (Bubenko, 1986; Westrup, 1993). Indeed, this has been quite aptly labelled as a "bipolar drift (in which) both poles are cold" (Chang, 1990). The papers in this issue have all sought to address this gap between theory and practice and consider how practical initiative could be undertaken to

This paper began with an aphorism, and another that is clearly relevant here is that there is nothing so practical as a good theory. Sahay and Walsham (1995) have suggested that research which strongly engages with theory can help bridge the gap between theory and practice. Such writing serves to go beyond the once-off type of research paper which neither locates itself in any cumulative theoretical context, nor considers the implications for practice of the findings. Heeks (2001) captures the essential problem of this scenario very well, and it is a good point on which to conclude:

...the majority of theory-engaged writing...draws from practice to inform writing but fails to then develop findings of practical value. Yet the ultimate purpose of theory must not be just to provide a better understanding of the world but also to provide the basis for better interventions in that world.

\section{References}

Benbasat, I. \& Zmud, R. (1999). Empirical research in IS: the practice of relevance, MIS Quarterly, Vol. 23, No. 1, pp. 3-16.

Bubenko, J. (1986). Information system methodologies -- a research view. In Olle et al. (1986). Information Systems Design Methodologies: Improving the Practice, 289-318. North-Holland,

Chang, C. (1990). Editor's message: Let's stop the bipolar drift. IEEE Software, May, 4.

Denning, P. (1993). Designing new principles to sustain research in our universities, Communications of the ACM, Vol. 36, No. 7, pp. 99-104.

Heeks, R. (2001). Academic writings on information systems and development. IFIP Newsletter, Vol. 18, No. 3, 9-10.

Heart, T. (2001). IS relevance (maybe we're asking the wrong questions). Email 15 Feb 2001, Available at http://www.commerce.uq.edu.au/isworld/research/msg.22-02-2001.html

Khazanchi, D. (2001). IS research relevance: Informal survey. Email available at http://www.commerce.uq.edu.au/isworld/research/msg.22-02-2001.html

Lerner, J. \& Tirole, J. (2000). The simple economics of open source. Harvard Business School Working Paper \#00-059. 
McLean, E. (1973). In Van Horn, R. Empirical studies of management information systems. DataBase, Winter, $172-180$.

Sahay, S. \& Walsham, G. (1995). Information technology in developing countries: a need for theory building. Information Technology for Development, 6(3/4), 111-124

Wainwright, D. (2000). Consultancy, learning and research: the on-going debate over rigour versus relevance in IS research. Proceedings of the 10th BIT Annual Conference, e-futures, Manchester Metropolitan University, November.

Westrup, C. (1993). Information system methodologies in use. Journal of Information Technology, 8, $267-275$.

Williams, J. (2001). IS research relevance, Email 11 Feb 2001, available at http://www.commerce.uq.edu.au/isworld/research/msg.22-02-2001.html

\section{Biography}

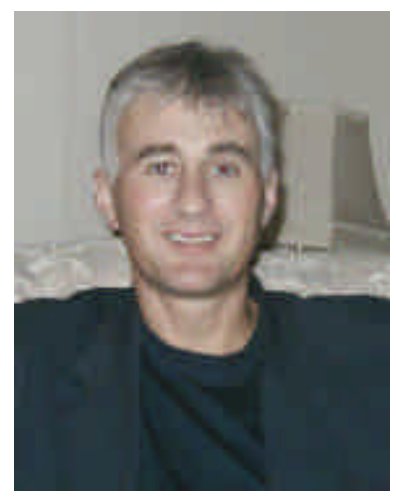

Brian Fitzgerald holds the Frederick A. Krehbiel II Chair in Innovation in Global Business and Technology at the University of Limerick, Ireland. He has a $\mathrm{PhD}$ from the University of London and has also held positions as Visiting Professor at Northern Illinois University in the US and the University of Gothenburg in Sweden. He is Associate Editor for The Information Systems Journal, and Data Base, two leading international journals in the IS field. His publications include six books and more than 60 papers, published in leading international conferences and journals. Having worked in industry prior to taking up an academic position, he has more than 20 years experience in the IS field. 